\title{
Are the winters 2010 and 2012 archetypes exhibiting extreme opposite behavior of the North Atlantic jet stream?
}

Article

Accepted Version

Santos, J. A., Woollings, T. and Pinto, J. G. (2013) Are the winters 2010 and 2012 archetypes exhibiting extreme opposite behavior of the North Atlantic jet stream? Monthly Weather Review, 141 (10). pp. 3626-3640. ISSN 1520-0493 doi: https://doi.org/10.1175/MWR-D-13-00024.1 Available at https://centaur.reading.ac.uk/32731/

It is advisable to refer to the publisher's version if you intend to cite from the work. See Guidance on citing.

Published version at: http://journals.ametsoc.org/doi/abs/10.1175/MWR-D-13-00024.1

To link to this article DOI: http://dx.doi.org/10.1175/MWR-D-13-00024.1

Publisher: American Meteorological Society

Publisher statement: (C) Copyright 2009 of the American Meteorological Society. The AMS Copyright Policy is available on the AMS web site at http://www.ametsoc.org.

All outputs in CentAUR are protected by Intellectual Property Rights law, including copyright law. Copyright and IPR is retained by the creators or other copyright holders. Terms and conditions for use of this material are defined in the End User Agreement. 


\section{CentAUR}

Central Archive at the University of Reading

Reading's research outputs online 


\title{
1 Are the winters 2010 and 2012 archetypes exhibiting extreme
}

2

\section{opposite behavior of the North Atlantic jet stream?}

\author{
João A. Santos ${ }^{1}$ \\ Centre for the Research and Technology of Agro-Environmental and Biological \\ Sciences (CITAB), University of "Trás-os-Montes e Alto Douro”, Portugal \\ Tim Woollings \\ Department of Meteorology, University of Reading, Reading, United Kingdom \\ Joaquim G. Pinto \\ Department of Meteorology, University of Reading, Reading, United Kingdom and \\ Institute for Geophysics and Meteorology, University of Cologne, Cologne, Germany
}

\footnotetext{
${ }^{1}$ Corresponding author address: J. A. Santos, Departamento de Física, Universidade de Trás-os-Montes e Alto Douro, P. O. Box 1013, 5001-801 Vila Real, Portugal

E-mail: jsantos@utad.pt
} 
The atmospheric circulation over the North Atlantic-European sector experienced exceptional but highly contrasting conditions in the recent 2010 and 2012 winters (November-March; with the year dated by the relevant January). Evidence is given for the remarkably different locations of the eddy-driven westerly jet over the North Atlantic. In the 2010 winter the maximum of the jet stream was systematically between $30^{\circ} \mathrm{N}$ and $40^{\circ} \mathrm{N}$ (in the 'south jet regime'), while in the 2012 winter it was predominantly located around $55^{\circ} \mathrm{N}$ (north jet regime). These jet features underline the occurrence of either weak flow (2010) or strong and persistent ridges throughout the troposphere (2012). This is confirmed by the very different occurrence of blocking systems over the North Atlantic, associated with episodes of strong cyclonic (anticyclonic) Rossby wave breaking in 2010 (2012) winters. These dynamical features underlie strong precipitation and temperature anomalies over parts of Europe, with detrimental impacts on many socioeconomic sectors. Despite the highly contrasting atmospheric states, mid and high-latitude boundary conditions do not reveal strong differences in these two winters. The two winters were associated with opposite ENSO phases, but there is no causal evidence of a remote forcing from the Pacific sea surface temperatures. Finally, the exceptionality of the two winters is demonstrated in relation to the last 140 years. It is suggested that these winters may be seen as archetypes of North Atlantic jet variability under current climate conditions.

Keywords: jet stream, blocking, wave-breaking, SPRE, precipitation, North AtlanticEuropean sector, extreme winters 
36 1. Introduction

37 Weather and climate over Europe are strongly dependent on the large-scale atmospheric circulation over the North Atlantic (NA) area (e.g. Wanner et al. 2001). During the two recent winters of 2009/10 and 2011/12 (hereafter winters 2010 and 2012), the dynamical conditions over the NA were completely different, showing a dramatic range of variability in terms of the large-scale atmospheric flow. Therefore, the analysis of these two highly contrasting winters helps to clarify the mechanisms underlying the atmospheric variability over the NA under current climate conditions. Among the possible diagnostics for this variability, the eddy-driven westerly jet is an important indicator of the physical state of the tropospheric circulation within the Euro-Atlantic sector. In particular, its latitude and speed have been shown to be suitable measures of the largest scale circulation over this region (Woollings et al. 2010a). When considering the jet latitude, the two winters 2010 and 2012 lie at the opposite extremes of the spectrum of variability, and so it is useful to describe the dynamical features of these winters as possible archetypes of NA jet variability.

The latitude of the NA jet stream and the occurrence of anticyclonic Rossby wavebreaking (RWB) over southwestern Europe were also shown to be related to strong and persistent ridge episodes (SPRE) over the eastern NA (Santos et al. 2009; Woollings et al. 2011). Further, the close relationship between RWB and blocking systems was already discussed in several previous studies (e.g. Altenhoff et al. 2008; Berrisford et al. 2007; Gabriel and Peters 2008; Pelly and Hoskins 2003; Tyrlis and Hoskins 2008). Blocking is traditionally identified using indices based on the reversal of the meridional gradient of the mid-tropospheric geopotential height (e.g. Barriopedro et al. 2006; Tibaldi and Molteni 1990). The interplays between RWB / blocking and the North 

pattern or the stratospheric variability have also been widely discussed (e.g. CrociMaspoli et al. 2007; Masato et al. 2012; Woollings and Hoskins 2008; Woollings et al. 2008; Woollings et al. 2010b). In a recent study, Davini et al. (2012) underlined the differences between the (more frequent) high-latitude and mid-latitude blockings (also called European blockings) in the NA, which are driven by cyclonic and anticyclonic RWB, respectively (see also Weijenborg et al. 2012).

The large-scale atmospheric conditions over the NA are of central importance for the weather and climate over the European continent. Recent studies show that the occurrence of weather and climate extremes may have increased on the global scale (Field et al. 2012). In particular, there is increasing evidence that anthropogenic forcing is gradually changing both the strength and frequency of temperature and precipitation extremes (Hansen et al. 2012). The large-scale atmospheric circulation over the NA strongly controls not only the mean precipitation and temperature fields over Europe, but also their extremes, particularly in winter, as demonstrated by many previous teleconnection patterns of the atmospheric variability in the NA-European sector and closely related to jet variability (Hurrell et al. 2001; Pinto and Raible 2012; Wallace and Gutzler 1981; Wanner et al. 2001). As persistent anomalies in the atmospheric flow al. 2012), the understanding of their driving mechanisms can provide valuable 
which are of significant value for many socioeconomic sectors. As a result of the anomalies in the large-scale circulation in the 2010 and 2012 winters, strong anomalies in both precipitation and temperature were recorded all across Europe. While the 2010 winter was anomalously wet over southern Europe (Andrade et al. 2011; VicenteSerrano et al. 2011) and was also characterized by strong cold outbreaks in northern Europe (Moore and Renfrew 2012; Wang et al. 2010), the 2012 winter was anomalously dry in southern Europe and anomalously warm in northern Europe, as will be shown below. As such, the present study also aims to systematize some dynamical features associated with the occurrence of near surface atmospheric extremes over Europe on a seasonal basis.

In this study, the main goals are twofold: 1) to provide further insight into the dynamical features of these extreme winters; 2) to give a long-term perspective of their likelihood and exceptionality. An underlying motivation is to assess the extent to which these winters may be seen as archetypes of NA jet variability. The manuscript is organized as follows: data and methods are described in section 2. The results are presented and discussed in section 3. Lastly, section 4 presents an overview of the most significant outcomes and conclusions.

\section{Data and methods}

The National Centers for Environmental Prediction (NCEP) / National Center for Atmospheric Research (NCAR) reanalysis dataset (Kistler et al. (2001); hereafter NCEP-NCAR reanalysis) in the period 1950-2012 is used for characterizing the largescale atmospheric circulation in the winters of 2010 and 2012. This dataset has a spatial resolution of $2.5^{\circ}$ latitude $\times 2.5^{\circ}$ longitude and a temporal resolution of $6 \mathrm{~h}$. Unless 

Forecasts (ECMWF) ERA-Interim reanalysis (Dee et al. 2011), with atmospheric fields on a $1.5^{\circ}$ latitude $\times 1.5^{\circ}$ longitude grid and at a 6-hourly time resolution, is also used as a basis for the characterization of the 2-PVU (Potential Vorticity Unit) potential temperature during the two selected winters. This dataset is improved with respect to the ECMWF ERA-40 reanalysis (Uppala et al. 2005) and is regularly updated. The period analyzed is November-March.

Furthermore, the NA eddy-driven jet latitude characterization and the SPRE detection

117 are also carried out using the Twentieth Century Reanalysis (Compo et al. (2011); hereafter 20CR). As this dataset comprises information on the uncertainty of the atmospheric fields, by providing a 56-member ensemble over a relatively long time period (1871-2010; 140 years), it allows estimations of the uncertainties inherent to each diagnostic. The $20 \mathrm{CR}$ fields are defined on a $2^{\circ}$ latitude $\times 2^{\circ}$ longitude grid at 6 hourly time spacing. As the $20 \mathrm{CR}$ is mainly used to provide a long-term perspective of the range of variability of the features analyzed in the present study (jet index and SPRE), it is not a major shortcoming that data for the 2012 winter is not available. diagnostic tools of the large-scale atmospheric flow over the eastern NA. The jet index computation is described in Woollings et al. (2010a). Essentially the method determines an average jet latitude and speed across the NA, by averaging the zonal wind over 0$60^{\circ} \mathrm{W}$ and smoothing with a 10-day low-pass filter before finding the maximum speed. In the original method, the zonal wind was additionally averaged over pressure levels between 925 and $700 \mathrm{hPa}$. Here, however, only the $850 \mathrm{hPa}$ level has been used, as it is the only isobaric level within the $925-700 \mathrm{hPa}$ layer available in the 20CR. A 
comparison between the jet indices calculated using either $850 \mathrm{hPa}$ or $925-700 \mathrm{hPa}$ has been made using ERA-40 data, but very similar results are obtained (not shown). The rationale of this approach is to isolate the eddy-driven component of the zonal flow by using only lower tropospheric data. Woollings et al. (2010a) provided evidence that the jet latitude variability projects both onto the NAO and EA patterns. As such, the method provides physical quantities which describe much of the same variability as the NAO and EA.

The blocking detection method is taken from a previous study by Scherrer et al. (2006). This index is a straightforward extension of the classical Tibaldi and Molteni (1990) index into two dimensions (latitude and longitude). The index has the advantage that it can be readily calculated from reanalysis data using daily mean $500 \mathrm{hPa}$ geopotential heights. It is very similar to the index used by Davini et al. (2012) and gives a similar climatology of blocking to that of Masato et al. (2012). Both of the classical constraints are applied: 1) that the meridional geopotential height gradient is reversed at a given point and 2) that the flow is westerly to the north of the point, with a height gradient stronger than $10 \mathrm{~m}$ per degree of latitude. Finally, a 5-day persistence criterion is applied to each grid point before it can be considered as part of a block. Note that the region identified as blocked corresponds roughly to the location of the anticyclone of the blocking dipole, rather than the location of flow reversal as in some other indices.

The SPRE are identified following the same methodology as in Santos et al. (2009) and Woollings et al. (2011), but for an extended wintertime period (November-March) and using the $500 \mathrm{hPa}$ geopotential height (Z500) rather than the $250 \mathrm{hPa}$ geopotential height. The choice of a different isobaric level enabled a direct comparison among different datasets (in particular, the $250 \mathrm{hPa}$ level is not available in the 20CR for all 
ensemble members). Nevertheless, there is a high consistency between results using these two isobaric levels (not shown). Herein, a SPRE corresponds to an episode that persists at least 10 days with a Z500 zonal mean departure, averaged over the sector $\left[40-50^{\circ} \mathrm{N}, 40^{\circ} \mathrm{W}-5^{\circ} \mathrm{E}\right]$, higher than 140 gpm. This threshold approximately corresponds to the $60^{\text {th }}$ percentile of the distribution of the wintertime zonal mean departures over 162 the baseline period of 1950-2012. It guarantees that only strong ridge events are considered, but with a sufficiently high number of episodes being isolated. The zonal departures are computed with respect to a second-order polynomial adjusted to the daily climate-means (baseline period of 1950-2012) of the Z500 zonal-means over the full winter period ( $1^{\text {st }}$ of November to $31^{\text {st }}$ of March). All SPRE are separated by at least 3 days. A list of 85 SPRE in the period 1950-2012 is provided in Table S1, together with their corresponding onsets and decays, lengths (in days) and strengths (area-means of the zonal mean departures).

The cyclone activity for the two winters was quantified by a cyclone tracking algorithm, originally developed by Murray and Simmonds (1991) and adapted for the NA cyclone characteristics by Pinto et al. (2005). The methodology was applied to the NCEPNCAR reanalysis over the baseline period in order to compute the cyclone track density and the corresponding anomalies for the two selected winters. The method compares well with results by other tracking methods and is able to follow cyclones from the early stages of cyclone development until dissipation (Neu et al. 2013).

In summary, three reanalysis databases (NCEP-NCAR, ERA-Interim and 20CR) are used in the present study so that several diagnostics can be calculated and compared, making use of their different advantages and availabilities. The ERA-Interim reanalysis provides improved atmospheric fields at relatively high spatial resolution. However, 


\section{$186 \quad 3 . \quad$ Results}

owing to its short period of available data (1979-2012) other reanalysis need to be considered so as to improve the statistical significance of the results (larger sample sizes). This constraint explains the preferential use of the NCEP-NCAR reanalysis and of the 20CR within the scope of the present study.

187 a. Jet signatures

The highly contrasting atmospheric conditions during the two recent winters (November-March) of 2010 and 2012 are clearly manifested by in the jet stream features. The latitude-time Hovmöller diagrams of the $850 \mathrm{hPa}$ zonal wind component, averaged within the $0-60^{\circ} \mathrm{W}$ longitude sector (central and eastern NA), clearly highlight the different dynamical regimes that prevailed in the two winters (left panels in Fig. 1). The axis of the maximum westerly flow (illustrated by the daily latitudes of the zonal wind maxima) is within the latitude sector of $30-50^{\circ} \mathrm{N}$ most of the time in the 2010 winter, while it tended to be polewards of the $50^{\circ} \mathrm{N}$ parallel in the 2012 winter. In both winters the westerly flow is generally strong on a daily basis $\left(20-30 \mathrm{~m} \mathrm{~s}^{-1}\right)$ and is flanked by comparatively weak easterly flows at higher and lower latitudes.

The corresponding histograms of the jet latitude index (right panels in Fig. 1) reveal that the jet is often close to its southernmost (northernmost) location in the winter of 2010 (2012). In fact, the jet location is almost always equatorwards of the $50^{\circ} \mathrm{N}$ parallel during the 2010 winter, particularly from mid-December onwards, while in the 2012 winter it is mostly located polewards of the $50^{\circ} \mathrm{N}$ parallel, predominantly from late 
trimodal distribution of the jet latitude (preferred locations) in winter (Woollings et al. 2011; distributions shown in their Fig. 1), it can be stated that during the winter of 2010 both the southern and mid-latitude flow regimes are dominant, while in 2012 the northern flow is by far the leading regime. The most pronounced exceptions to these general features occurred in early December 2009 and late January 2010 (in the 2010 winter), when the jet was in its northern flow regime, and in November 2011 and March 2012 (in the 2012 winter), when the jet was temporarily shifted southwards. The close relationship between the jet latitude over the NA and the NAO phase is also reflected in the strong phase opposition of the NAO pattern during the two winters (NovemberMarch): -1.18 (2010) and +1.35 (2012). In fact, these extreme values correspond to the 5th (2010) and 98th (2012) percentiles of the full distribution of the November-March mean NAO in 1950-2012, according to the Climate Prediction Center (CPC) NAO index (http://www.cpc.ncep.noaa.gov/). If the shorter season of December-February is considered instead, the negative NAO of the 2010 winter becomes more extreme (Osborn 2011).

\section{b. Dynamical diagnosis}

221 The longitude-time Hovmöller diagrams of the daily $500 \mathrm{hPa}$ geopotential height 222 anomalies from the instantaneous zonal-mean, averaged within the latitude sector of 40$50^{\circ} \mathrm{N}$ and for the winters of 2010 and 2012, underline their remarkably different dynamical characteristics (Fig. 2). Strong negative anomalies are found over the NA $\left(90-30^{\circ} \mathrm{W}\right)$ in the 2010 winter, while the persistence of the strong positive anomalies over the Eastern NA $\left(40^{\circ} \mathrm{W}-5^{\circ} \mathrm{E}\right)$ is very pronounced in the 2012 winter. For both

227 winters, the eastwards propagation of high-frequency anomalies from the eastern North 
Pacific $\left(120-180^{\circ} \mathrm{W}\right)$ towards the NA $\left(0-60^{\circ} \mathrm{W}\right)$ is also found. The connections between the NA sector and the North Pacific mid-latitudes have been discussed in previous studies (Castanheira and Graf 2003; Honda et al. 2005; Pinto et al. 2011).

For the 2012 winter, the strong cores of positive anomalies over the Eastern NA divert the mid-latitude low pressure systems, and their associated fronts, to higher latitudes, leading to a blocking of the eastward traveling cyclones (Rex 1950). The blocking frequencies for each winter hint at the very different conditions in the 2010 and 2012 winters (Fig. 3). While in 2010 blocking occurrences over the NA were anomalously high (low) polewards (equatorwards) of the $60^{\circ} \mathrm{N}$ parallel, a nearly opposite pattern occurred in 2012. Blocking was therefore prevalent in both winters with the difference being that this lay largely on the north side of the southward displaced jet in 2010 and largely on the south side of the northward displaced jet in 2012. In fact, blocking occurred over Scotland and southern Scandinavia in both winters, although with the jet lying to the south in 2010 and to the north in 2012. In the northeastern region of Europe, the blocking anomalies are actually quite similar for the two winters. This region appears to be far enough downstream that the blocking is more or less independent of the Atlantic jet position.

The strong blocking over and near Greenland in 2010 is consistent with the strongly negative NAO in this winter, since these two features are closely related in general (Croci-Maspoli et al. 2007; Woollings et al. 2008). Woollings et al. (2011) found that while blocking over southern Europe does tend to accompany the SPRE and northward Atlantic jet shifts, the relationship is less strong than that between Greenland blocking and southward jet shifts. It is interesting that the overall picture is of as much blocking in 2012 as in 2010, with equally large blocking anomalies in both winters. At least for 
these extreme cases then, it seems that blocking can be important for both northward and southward shifts of the jet. Also note that, as in Davini et al. (2012), the index used here finds more blocking events at lower latitudes than the PV-based index of Woollings et al. (2011), which may be a factor here.

The contrasting dynamical features can also be emphasized by the unprecedented high number of SPRE days in the winter of 2012 (70 days), while the winter of 2010 shows no SPRE occurrences (Table S1). The dynamical conditions underlying the SPRE are highlighted by the composites of the $500 \mathrm{hPa}$ geopotential height and temperature anomalies only for SPRE days, along with the corresponding $250 \mathrm{hPa}$ geopotential height anomalies (cf. Fig. S1 in supplemental material). As expected, taking into account the SPRE definition, a positive anomaly with a nearly equivalent barotropic structure is apparent over the Eastern NA. Note that the maximum positive anomaly in the $500 \mathrm{hPa}$ geopotential height (nearly 140 gpm; Fig. S1) is lower than the average strength of the SPRE (about 214 gpm; Table S1). In fact, owing to the climate-mean ridge over the eastern NA, the zonal mean departures of the $500 \mathrm{hPa}$ geopotential height used in the SPRE definition are predominantly higher than the temporal anomalies at each grid point over the same region. A negative and westward tilted with height (baroclinic) anomaly can also be found over higher latitudes, as well as a second positive core over North America. The composite for the $250 \mathrm{hPa}$ streamlines (Fig. S1) not only gives evidence for a blocking of the westerly flow over Europe, but also suggests the presence of anticyclonic RWB. This is in line with the previous findings that wave-breaking acts to amplify the SPRE anomaly and likely increase its persistence

274 (Woollings et al. 2011). Furthermore, the overall dynamical structure of the SPRE 275 (equivalent barotropic ridges), as well as the associated anticyclonic RWB, are in clear agreement with both the NA low-latitude blocking and the European blocking discussed 
277 by Davini et al. (2012). Since the SPRE are defined as geopotential anomalies 278 northwards of the $40^{\circ} \mathrm{N}$ parallel, they conform more to the so-called European 279 blockings, which can actually block the prevailing westerly flow (rather than divert it). 280 Although further research is needed to improve the current understanding of the 281 mechanisms underlying the SPRE onset, development and decay, such a dynamical 282 attribution analysis is out of the scope of the present study, as the SPRE classification is here used only as a diagnostic tool to characterize the atmospheric conditions over the study area.

The composites of the potential temperature on a 2-PVU surface (near the tropopause level) clearly highlight the remarkable differences between these two winters (Fig. 4). In fact, the mean flow is largely zonal over the eastern NA in 2010, suggesting high transiency, while it presents a strong ridge with a southwest-northeast tilt over the same region in 2012, this time suggesting a relatively high stationarity in the flow over the eastern NA. This ridge in the mean flow is indeed a manifestation of strong and frequent anticyclonic RWB in the 2012 winter. This statement can be clearly illustrated for a 3-day period in the 2012 winter (2-4 December 2011; Fig. 4, based on ERAInterim), when a large-scale anticyclonic meridional overturning of the 2-PVU potential temperature is apparent. It starts with a major poleward advection of a relatively warm (subtropical) air mass that is followed by anticyclonic RWB (Fig. 4). The anticyclonic RWB in the following days underlies the persistence of this strong eddy, justifying its classification as a SPRE (number 83; Table S1 in supplemental material). This event effectively corresponds to a 10-day length SPRE (1-10 December 2011) with 215 gpm strength. Similar considerations can be extrapolated to many other days during the 2012 winter (not shown), taking into consideration that 70 days out of 152 (NovemberMarch) were keyed as SPRE days (Table S1). On the other hand, an episode of cyclonic 
RWB over high latitudes of the NA (30 January-3 February 2010; Fig. 4) demonstrates

303 the opposite conditions in the 2010 winter. This period shows a large mass of 304 subtropical, high potential temperature air advecting northward and overturning cyclonically, in the process of forming a cut-off anticyclone over Greenland. This event is a classic example of the cyclonic wave-breaking associated with the negative NAO phase (Benedict et al. 2004; Woollings et al. 2008).

The cyclone track densities and the corresponding anomalies for the two winters are in close agreement with the flow characteristics described above (Fig. 5). Anomalously high cyclone track densities are found over the eastern NA, Western Europe and the Mediterranean Basin in 2010, whereas anomalously low densities can be found over the British Isles, the eastern NA and parts of central Europe. In both winters, opposite anomalies can be found over the high-latitude NA, mainly in the vicinity of Iceland. It is interesting that the Mediterranean storm track is not anomalously weak in 2012, and even shows above average cyclone activity over the Eastern Mediterranean.

As a result of the aforementioned shifts in the jet location, and associated changes in the frequencies of occurrence of cyclones over the NA, the resulting patterns of the total winter precipitation are remarkably different between the two winters, largely reflecting the mean path of the westerly jet in each winter (Fig. 5). While the axis of maximum precipitation over the NA was largely zonal (along the $40^{\circ} \mathrm{N}$ parallel) in the 2010 winter, it was southwest-northeastwardly tilted in the 2012 winter. As such, the 2010 winter was anomalously dry (wet) over some areas of northern (southern-central)

323 Europe, whereas nearly the opposite occurred in the 2012 winter. More specifically, 324 these differences are particularly strong over the mid-latitude NA and southwestern Europe and, with opposite signal, over the high latitudes of the NA and the Norway- 
326 Norwegian Sea region. With respect to the $2 \mathrm{~m}$ air temperature anomalies, the contrast

327 between the two winters is remarkable (Fig. 5). The 2010 winter was anomalously cold 328 over Northern Europe and along the mean path of the cyclone track and warm over northeastern Canada and North Africa. Nearly the opposite pattern occurred in the 2012 winter. These precipitation and temperature anomalies are in clear agreement with the differences in the large-scale circulation over the NA in the two winters.

332 An obvious question is whether there were any strong anomalies in boundary conditions which could have helped to cause the atmospheric anomalies. It should always be remembered that extreme events can arise from purely chaotic atmospheric dynamics, so that a forcing external to the atmosphere is not necessary in general. Recent work by Jung et al. (2011) suggested that the extreme negative NAO winter of 2010 was not predictable, at least by their model experiments using several potential driving mechanisms. However, there is considerable evidence that variations in boundary conditions do have some influence on interannual variability over the North Atlantic (e.g. Greatbatch et al. 2012). Here we simply compare and contrast some of the anomalous boundary conditions for these winters and discuss their potential roles.

342 Regarding the sea surface temperature (SST) anomalies for the two winters, an 343 important external forcing of the atmospheric circulation, important differences can be 344 found in the tropical Pacific, as well as in the subtropical NA (Fig. 6a, b). In the 2010 winter a positive El-Niño Southern Oscillation (ENSO; Peixoto and Oort,1992) pattern is accompanied by an anomalously warm subtropical NA, while in the 2012 winter a negative ENSO pattern can be found with no significant anomalies in the subtropical NA. The opposite phases of ENSO are confirmed by the Oceanic Niño Index (ONI) of the CPC (http://www.cpc.ncep.noaa.gov/) which has values of +1.6 and -0.9 for 
350 December-February 2010 and 2012, respectively. In contrast, the SST anomalies for 351 both winters are very similar in the mid-latitude NA and in the Artic. Furthermore, the 352 Arctic ice cover leading both winters (October-November) is also very similar (not 353 shown). Therefore, it is unlikely that mid and high-latitude boundary conditions can 354 explain the strong differences between the two winters.

355 However, the contrasting remote boundary conditions in the tropical Pacific are 356 plausible driving mechanisms, as suggested by several previous studies (Müller et al. 357 2008; Trenberth et al. 1998). In fact, the composite anomalies of the $250 \mathrm{hPa}$ zonal 358 wind component and of the $500 \mathrm{hPa}$ geopotential heights (Fig. 6c, d) show similar anomalies spanning the Pacific and Atlantic basins. In the 2010 winter there is a tripole in the wind anomalies over the NA, with its mid-latitude positive anomalies extending upwind towards the North Pacific. The Aleutian low is also anomalously weak and the pattern in the NA clearly reflects the negative NAO phase. On the other hand, in the 2012 winter, the signals of the wind anomalies are generally reversed and are in conformity with an anomalously strong Aleutian low and a positive NAO phase (cf. Woollings et al. 2011, their Fig. 6c). It is possible that a connection between the ENSO phase and the NA flow could have occurred through the Pacific-North American Pattern (PNA; Wallace and Gutzler 1981). Many previous studies have identified several mechanisms that could explain North Pacific-NA (NP-NA) coupling such as this (Castanheira and Graf 2003; Honda et al. 2005; Pinto et al. 2011). A major sudden stratospheric warming (SSW) was also recorded in the 2010 winter (Dornbrack et al. 2012), as also reported by the NOAA ${ }^{2}$. The occurrence of a SSW has been associated with NP-NA coupling, mainly through vertical Rossby wave propagation and

\footnotetext{
${ }^{2}$ NOAA Weather Service - Climate Prediction Center; http://www.cpc.ncep.noaa.gov/products/stratosphere/)
} 
troposphere-stratosphere coupling (Ineson and Scaife 2009), and with tropospheric blocking (Castanheira and Barriopedro 2010).

375 A brief statistical analysis has been performed and this reveals no clear signature in the Pacific SSTs in other winters with very strong Atlantic jet anomalies (not shown). This demonstrates that there is not a general and permanent link between these features. In fact, a possible ENSO-like influence has been suggested to be non-stationary in time due to modulation by multi-decadal oscillations of SST anomalies over the Atlantic and Pacific basins (e.g. Greatbatch et al. 2004; Zanchettin et al., 2008; López-Parages and Rodríguez-Fonseca, 2012). Numerical modeling experiments would be required to investigate the likelihood of tropical Pacific influence in these two winters more fully.

As previously mentioned, the $20 \mathrm{CR}$ is also used so as to better assess the variability in both the jet stream latitude and in the number of SPRE days, by using a 56-member ensemble over a relatively long time period (1871-2010; 140 years). Figure 7a shows box plots of the winter mean jet latitude, derived by averaging the daily values over the November-March period. This shows similar empirical distributions for the NCEPNCAR reanalysis and the 20CR, despite the larger sample size in 20CR (140 winters) than in NCEP (63 winters). These distributions are nearly symmetric (almost zero skewness) and only one outlier is observed for the NCEP distribution (from the NCEPNCAR reanalysis). The mean jet latitudes are $41^{\circ} \mathrm{N}$ in 2010 and $53^{\circ} \mathrm{N}$ in 2012 , which are located at the very tails of both distributions, particularly in 2010 (Fig. 7a). The strong dependency of the SPRE detection on fixed thresholds (area-mean Z500 zonal mean departures greater than 140 gpm, lasting at least 10 days and separated by at least 3 
days) explains the strong positive skewness in their distributions (Fig. 7b); the skewness coefficient is statistically significant at a confidence level of $99 \%$. The existence of several positive outliers in the 20CR distribution is also noteworthy, showing strong variability in this diagnostic. As previously stated, the winter of 2012 exhibits the highest number of SPRE days (3 SPRE with a total of 70 days) of the entire record for 402 the NCEP distribution and corresponds to a positive outlier in the 20CR distribution 403 (Fig. 7b). On the contrary, the winter of 2010 shows no SPRE occurrences (Fig. 7b), i.e. 404 the absolute minimum in both distributions, by definition of the SPRE. These findings are indeed a manifestation of extraordinarily anomalous dynamical conditions that prevailed during the two winters.

In the analysis of the temporal variability for 20CR, medians across the ensemble are used instead of means, as they are a more robust central tendency measure than the latter (they are less sensitive to outliers), though the results remain nearly unchanged (not shown). The chronograms of the jet latitude (Fig. 7c) and of the number of SPRE days (Fig. 7d) reveal a clear agreement between both reanalysis datasets (NCEP and 20CR) in their common period of 1950-2010 (grey vs. black bars and orange vs. red curves in Fig. 7c, d). This high correspondence for the jet latitude is corroborated by a correlation coefficient between its 11-yr moving averages for NCEP and 20CR of 0.99 (statistically significant at a confidence level of 99\%). For the number of SPRE days, the correlation coefficient is 0.94 , also statistically significant at a confidence level of 99\%. As referred to above, due to the SPRE definition, which relies on specific spatial and temporal criteria, slight differences in the daily Z500 fields explain some important 419 discrepancies not only amongst the 20CR ensemble members, but also between 20CR and NCEP-NCAR outcomes. 
421 The chronograms also reveal the presence of slight long-term trends in the ensemble 422 medians of the two measures (red curves in Fig. 7c, d). In both the mean jet latitude and 423 in the number of SPRE days, the 11-yr moving averages of the ensemble medians only 424 show relatively weak decadal trends. The blue lines in turn give an indication of 425 changes in inter-annual variability over time. This is done by taking the median across 426 the ensemble as before, but this time plotting the $25^{\text {th }}$ and $75^{\text {th }}$ percentiles of the set of

42711 years in the moving window, hence summarizing the inter-annual variability in each 42811 year window. These show that these two extreme winters do not seem to be part of a long term trend towards higher inter-annual variability. Despite the upward trend in the number of NCEP SPRE days in the recent past (Fig. 7d), only a slight upward long-term trend (about +0.8 day/decade) is found over the whole 140-yr period (1871-2010), or even in the common period (1950-2012), using 20CR. This discrepancy can be explained by the stronger linear trend in the Z500 for NCEP than for the 20CR within the ridge sector of the SPRE definition (not shown). Furthermore, a spectral analysis of correlations) in the occurrence of SPRE days.

\section{Summary and conclusions}

441 Two recent and exceptional winters within the NA-European sector were selected in the 442 present study, with clear contrasts in their jet stream latitudes (Fig. 1): 2010 443 (southwardly shifted jet and frequent high-latitude blocking) and 2012 (northwardly 444 shifted jet and frequent low-latitude blocking). Owing to their strong impacts on many 
socioeconomic sectors throughout Europe (strong precipitation and temperature anomalies), their driving atmospheric dynamics deserve a better understanding, as well

447 as the assessment of their exceptionality, which are indeed the main purposes of this research. An analysis of the tropospheric flow hints at strong negative anomalies within the latitude sector of $40-50^{\circ} \mathrm{N}$ during the 2010 winter, whilst persistent and recurrent positive anomalies are found during the 2012 winter for the same latitudes (Fig. 2). These results are not only confirmed by the extreme NAO phases of the two winters, but also by the respective blocking frequencies (Fig. 3) and the SPRE occurrences (Table S1). The characteristic dynamical structure of the SPRE (Fig. S1), with a strong and persistent equivalent barotropic ridge over the eastern NA, maintained by anticyclonic RWB, was predominant in the 2012 winter (Figs. S1 and 4). Furthermore, the southwardly (northwardly) displaced jet in 2010 (2012) is reflected at the surface by similarly shifted paths of cyclone activity and corresponding precipitation anomalies over different parts of Europe (Fig. 5). The impacts of these shifts in the large-scale atmospheric flow on the precipitation totals for each winter are remarkable (Fig. 5). As a result, a diagnosis of the atmospheric conditions during these two winters elucidated the role played by the occurrence (absence) of three deeply intertwined dynamical features (SPRE / low-latitude blocking / anticyclonic-RWB) in triggering extreme winter conditions in Europe.

In most regards the two winters can be seen to be exact opposites of each other. Furthermore, they are both exceptional events, lying at the extreme opposite ends of the spectrum of variability. Therefore, these two winters may be seen as prime examples, or archetypes of the range of NA jet variability, at least under recent and current climate conditions. 
The winters of 2010 and 2012 had significant impacts on precipitation and temperature

470 over large areas of Europe. The contrasts are particularly noticeable between 471 southwestern and northern Europe (Fig. 5). Despite the extreme nature of these two 472 winters, the attribution of a single extreme event to either natural variability or 473 anthropogenic forcing remains a difficult task in climate research (Seneviratne 2012). 474 Nevertheless, some efforts have been recently made in order to address this issue, such as in explaining several extreme events that occurred worldwide during the year 2011 476 (Peterson et al. 2012). Furthermore, the observational precipitation data hint at a global intensification of the extremes in both tails of the precipitation distributions in the second half of the twentieth century (Min et al. 2011). In spite of the high complexity of the mechanisms governing precipitation and the resulting uncertainty in its climate change projections, enhanced extreme precipitation is expected in a future warmer climate (e.g. Field et al. 2012; Trenberth et al. 2003). Nonetheless, due to the relatively poor ability of climate models in reproducing blocking (Matsueda et al. 2009), the future projections and implications for precipitation are still challenging. As GCMs generally do not capture the full range of jet variability seen in observations (Anstey et al. 2013; Barnes and Polvani 2013; Hannachi et al. 2013), this raises concerns over their ability to predict changes in extreme regional precipitation. In forthcoming research it is aimed to specifically address this issue using control and forced runs from state-of-theart climate models.

We are indebted to the ECMWF for providing the ERA-Interim reanalysis data and to the NCEP for providing the NCEP-NCAR reanalysis data. This work is supported by 
493 European Union Funds (FEDER/COMPETE - Operational Competitiveness

494 Programme) and by Portuguese national funds (FCT - Portuguese Foundation for 495 Science and Technology) under the project FCOMP-01-0124-FEDER-022692. We 496 thank Belén Rodríguez-Fonseca (Univ. Complutense Madrid) for discussions. We 497 would also like to thank the two anonymous reviewers for their comments that have 498 helped to improve this manuscript.

499 
501 Altenhoff, A. M., O. Martius, M. Croci-Maspoli, C. Schwierz, and H. C. Davies, 2008: 502 Linkage of atmospheric blocks and synoptic-scale Rossby waves: a climatological 503 analysis. Tellus A, 60, 1053-1063.

504 Andrade, C., S. M. Leite, and J. A. Santos, 2012: Temperature extremes in Europe: 505 overview of their driving atmospheric patterns. Nat. Hazards Earth Syst. Sci., 12, 16715061691.

507 Andrade, C., J. A. Santos, J. G. Pinto, and J. Corte-Real, 2011: Large-scale atmospheric 508 dynamics of the wet winter 2009-2010 and its impact on hydrology in Portugal. Climate 509 Res., 46, 29-41.

510 Anstey, J. A., P. Davini, L. J. Gray, and T. Woollings, 2013: Multi-model analysis of 511 Northern Hemisphere winter blocking. Part I: Model bias and the role of resolution. $J$. 512 Geophys. Res. - Atmos., in press, doi:10.1002/jgrd.50231.

513 Barnes, E. A., and L. M. Polvani, 2013: Response of the midlatitude jets and of their 514 variability to increased greenhouse gases in the CMIP5 models. J. Climate, in press.

515 Barriopedro, D., R. Garcia-Herrera, A. R. Lupo, and E. Hernandez, 2006: A climatology 516 of northern hemisphere blocking. J. Climate, 19, 1042-1063.

517 Benedict, J. J., S. Lee, and S. B. Feldstein, 2004: Synoptic view of the North Atlantic 518 Oscillation. J. Atmos. Sci., 61, 121-144.

Berrisford, P., B. J. Hoskins, and E. Tyrlis, 2007: Blocking and Rossby wave breaking on the dynamical tropopause in the Southern Hemisphere. J. Atmos. Sci., 64, 28812898.

Castanheira, J. M., and H. F. Graf, 2003: North Pacific-North Atlantic relationships under stratospheric control? J. Geophys. Res. - Atmos., 108, 4036, doi:10.1029/2002JD002754.

525 Castanheira, J. M., and D. Barriopedro, 2010: Dynamical connection between 526 tropospheric blockings and stratospheric polar vortex. Geophys. Res. Lett., 37, L13809, 527 doi:10.1029/2010GL043819.

528 Cattiaux, J., P. Yiou, and R. Vautard, 2012: Dynamics of future seasonal temperature 529 trends and extremes in Europe: a multi-model analysis from CMIP3. Clim. Dynam., 38, $530 \quad 1949-1964$. 
531 Compo, G. P., and Coauthors, 2011: The Twentieth Century Reanalysis Project. Quart. 532 J. Roy. Meteor. Soc., 137, 1-28.

533 Croci-Maspoli, M., C. Schwierz, and H. C. Davies, 2007: Atmospheric blocking: space534 time links to the NAO and PNA. Clim. Dynam., 29, 713-725.

535 Davini, P., C. Cagnazzo, S. Gualdi, and A. Navarra, 2012: Bidimensional Diagnostics, 536 Variability, and Trends of Northern Hemisphere Blocking. J. Climate, 25, 6496-6509.

537 Dee, D. P., and Coauthors, 2011: The ERA-Interim reanalysis: configuration and 538 performance of the data assimilation system. Quart. J. Roy. Meteor. Soc., 137, 553-597.

539 Dornbrack, A., M. C. Pitts, L. R. Poole, Y. J. Orsolini, K. Nishii, and H. Nakamura, 540 2012: The 2009-2010 Arctic stratospheric winter - general evolution, mountain waves 541 and predictability of an operational weather forecast model. Atmos. Chem. Phys., 12, $542 \quad 3659-3675$.

543 Efthymiadis, D., C. M. Goodess, and P. D. Jones, 2011: Trends in Mediterranean 544 gridded temperature extremes and large-scale circulation influences. Nat. Hazards 545 Earth Syst. Sci., 11, 2199-2214.

546 Field, C. B., and Coauthors, 2012: Managing the Risks of Extreme Events and Disasters 547 to Advance Climate Change Adaptation: Summary for Policymakers. A Special Report 548 of Working Groups I and II of the Intergovernmental Panel on Climate Change. 549 Cambridge University Press, 19 pp.

550 Gabriel, A., and D. Peters, 2008: A Diagnostic Study of Different Types of Rossby 551 Wave Breaking Events in the Northern Extratropics. J. Meteorol. Soc. Japan, 86, 613552631.

553 García-Herrera, R., E. Hernández, D. Barriopedro, D. Paredes, R. M. Trigo, I. F. Trigo, 554 and M. A. Mendes, 2007: The Outstanding 2004/05 Drought in the Iberian Peninsula: 555 Associated Atmospheric Circulation. J. Hydrometeorol., 8, 483-498.

556 Greatbatch, R. J., J. Lu, and K. A. Peterson, 2004: Nonstationary impact of ENSO on 557 Euro-Atlantic winter climate. Geophys. Res. Lett., 31, L02208, 558 doi:10.1029/2003GL018542.

559 Greatbatch, R. J., G. Gollan, T. Jung, and T. Kunz, 2012: Factors influencing Northern 560 Hemisphere winter mean atmospheric circulation anomalies during the period 1960/61 561 to 2001/02. Quart. J. Roy. Meteor. Soc., 138, 1970-1982. 
562 Hannachi, A., E. Barnes, and T. Woollings, 2013: Behaviour of the winter North 563 Atlantic eddy-driven jet stream in the CMIP3 integrations. Clim. Dynam., in press, 564 doi:10.1007/s00382-012-1560-4.

565 Hansen, J., M. Sato, and R. Ruedy, 2012: Perception of climate change. Proc. Natl. 566 Acad. Sci., 109, 14726-14727, E2415-E2423, doi:10.1073/pnas.1205276109.

567 Honda, M., S. Yamane, and H. Nakamura, 2005: Impacts of the Aleutian-Icelandic 568 Low Seesaw on Surface Climate during the Twentieth Century. J. Climate, 18, 27935692802.

570 Hurrell, J. W., Y. Kushnir, and M. Visbeck, 2001: Climate. The North Atlantic 571 oscillation. Science, 291, 603-605.

572 Ineson, S., and A. A. Scaife, 2009: The role of the stratosphere in the European climate 573 response to El Nino. Nat. Geosci., 2, 32-36.

574 Jung, T., F. Vitart, L. Ferranti, and J. J. Morcrette, 2011: Origin and predictability of the 575 extreme negative NAO winter of 2009/10. Geophys. Res. Lett., 38, L07701, 576 doi:10.1029/2011GL046786.

577 Kenyon, J., and G. C. Hegerl, 2010: Influence of Modes of Climate Variability on 578 Global Precipitation Extremes. J. Climate, 23, 6248-6262.

579 Kistler, R., and Coauthors, 2001: The NCEP-NCAR 50-Year Reanalysis: Monthly 580 Means CD-ROM and Documentation. B. Am. Meteorol. Soc., 82, 247-267.

581 López-Parages, J., and B. Rodríguez-Fonseca, 2012: Multidecadal modulation of El 582 Niño influence on the Euro-Mediterranean rainfall. Geophys. Res. Lett., 39, L02704, 583 doi: 10.1029/2011GL050049.

584 Mahlstein, I., O. Martius, C. Chevalier, and D. Ginsbourger, 2012: Changes in the odds 585 of extreme events in the Atlantic basin depending on the position of the extratropical jet. 586 Geophys. Res. Lett., 39, L22805, doi:10.1029/2012GL053993.

587 Masato, G., B. J. Hoskins, and T. J. Woollings, 2012: Wave-breaking characteristics of 588 midlatitude blocking. Quart. J. Roy. Meteor. Soc., 138, 1285-1296.

589 Matsueda, M., R. Mizuta, and S. Kusunoki, 2009: Future change in wintertime 590 atmospheric blocking simulated using a 20-km-mesh atmospheric global circulation 591 model. J. Geophys. Res. - Atmos., 114, D12114, doi:10.1029/2009JD011919. 
Min, S. K., X. Zhang, F. W. Zwiers, and G. C. Hegerl, 2011: Human contribution to more-intense precipitation extremes. Nature, 470, 378-381.

Moore, G. W. K., and I. A. Renfrew, 2012: Cold European winters: interplay between the NAO and the East Atlantic mode. Atmos. Sci. Lett., 13, 1-8.

Müller, W. A., C. Frankignoul, and N. Chouaib, 2008: Observed decadal tropical Pacific-North Atlantic teleconnections. Geophys. Res. Lett., 35, L24810, doi:10.1029/2008GL035901.

Murray, R. J., and I. Simmonds, 1991: A numerical scheme for tracking cyclone centres from digital data. Part I development and operation of the scheme. Aust. Meteorol. Mag., 39, 155-166.

Neu, U., and Coauthors, 2013: IMILAST - a community effort to intercompare extratropical cyclone detection and tracking algorithms: assessing method-related uncertainties. B. Am. Meteorol. Soc., in press, doi:10.1175/BAMS-D-11-00154.1

Osborn, T. J., 2011: Winter 2009/2010 temperatures and a record-breaking North Atlantic Oscillation index. Weather, 66, 19-21.

Peixoto, J. P., and A. H. Oort, 1992: Physics of Climate. American Institute of Physics New York, 520 pp.

Pelly, J. L., and B. J. Hoskins, 2003: A new perspective on blocking. J. Atmos. Sci., 60, 743-755.

Peterson, T. C., P. A. Stott, and S. Herring, 2012: Explaining Extreme Events of 2011 from a Climate Perspective. Vol. 93, American Meteorological Society, 1041-1067 pp.

Pinto, J. G., and C. C. Raible, 2012: Past and recent changes in the North Atlantic oscillation. Wiley Interdiscip. Rev. - Clim. Change, 3, 79-90, doi: 10.1002/wcc.150.

Pinto, J. G., M. Reyers, and U. Ulbrich, 2011: The variable link between PNA and NAO in observations and in multi-century CGCM simulations. Clim. Dynam., 36, 337-354.

Pinto, J. G., T. Spangehl, U. Ulbrich, and P. Speth, 2005: Sensitivities of a cyclone detection and tracking algorithm: individual tracks and climatology. Meteorol. Z., 14, 823-838. 
620 Rex, D. F., 1950: Blocking Action in the Middle Troposphere and its Effect upon 621 Regional Climate. Tellus, 2, 196-211.

622 Santos, J., J. Corte-real, and S. Leite, 2007: Atmospheric large-scale dynamics during 623 the 2004/2005 winter drought in Portugal. Int. J. Climatol., 27, 571-586.

624 Santos, J. A., J. G. Pinto, and U. Ulbrich, 2009: On the development of strong ridge 625 episodes over the eastern North Atlantic. Geophys. Res. Lett., 36, L17804, 626 doi:10.1029/2009GL039086.

627 Scherrer, S. C., M. Croci-Maspoli, C. Schwierz, and C. Appenzeller, 2006: Two628 dimensional indices of atmospheric blocking and their statistical relationship with 629 winter climate patterns in the Euro-Atlantic region. Int. J. Climatol., 26, 233-249.

630 Seneviratne, S. I., and Coauthors, 2012: Changes in climate extremes and their impacts 631 on the natural physical environment. Cambridge University Press, 109-230 pp.

632 Tibaldi, S., and F. Molteni, 1990: On the operational predictability of blocking. Tellus $633 \quad A, \mathbf{4 2}, 343-365$.

634 Trenberth, K. E., A. Dai, R. M. Rasmussen, and D. B. Parsons, 2003: The changing 635 character of precipitation. B. Am. Meteorol. Soc., 84, 1205-1217.

636 Trenberth, K. E., G. W. Branstator, D. Karoly, A. Kumar, N. C. Lau, and C. 637 Ropelewski, 1998: Progress during TOGA in understanding and modeling global 638 teleconnections associated with tropical sea surface temperatures. J. Geophys. Res. 639 Oceans, 103, 14291-14324.

640 Trigo, R. M., D. Pozo-Vázquez, T. J. Osborn, Y. Castro-Díez, S. Gámiz-Fortis, and M. 641 J. Esteban-Parra, 2004: North Atlantic oscillation influence on precipitation, river flow 642 and water resources in the Iberian Peninsula. Int. J. Climatol., 24, 925-944.

643 Tyrlis, E., and B. J. Hoskins, 2008: Aspects of a Northern Hemisphere atmospheric 644 blocking climatology. J. Atmos. Sci., 65, 1638-1652.

645 Uppala, S. M., and Coauthors, 2005: The ERA-40 re-analysis. Quart. J. Roy. Meteor. 646 Soc., 131, 2961-3012.

647 Vicente-Serrano, S. M., and Coauthors, 2011: Extreme winter precipitation in the 648 Iberian Peninsula in 2010: anomalies, driving mechanisms and future projections. 649 Climate Res., 46, 51-65. 
650 Wallace, J. M., and D. S. Gutzler, 1981: Teleconnections in the Geopotential Height 651 Field during the Northern Hemisphere Winter. Mon. Weather Rev., 109, 784-812.

652 Wang, C. Z., H. L. Liu, and S. K. Lee, 2010: The record-breaking cold temperatures 653 during the winter of 2009/2010 in the Northern Hemisphere. Atmos. Sci. Lett., 11, 161654168.

655 Wanner, H., and Coauthors, 2001: North Atlantic Oscillation - Concepts and studies. 656 Surv. Geophys., 22, 321-382.

657 Weijenborg, C., H. de Vries, and R. J. Haarsma, 2012: On the direction of Rossby wave 658 breaking in blocking. Clim. Dynam., 39, 2823-2831.

659 Woollings, T., and B. Hoskins, 2008: Simultaneous Atlantic-Pacific blocking and the 660 Northern Annular Mode. Quart. J. Roy. Meteor. Soc., 134, 1635-1646.

661 Woollings, T., A. Hannachi, and B. Hoskins, 2010a: Variability of the North Atlantic 662 eddy-driven jet stream. Quart. J. Roy. Meteor. Soc., 136, 856-868.

663 Woollings, T., J. G. Pinto, and J. A. Santos, 2011: Dynamical Evolution of North 664 Atlantic Ridges and Poleward Jet Stream Displacements. J. Atmos. Sci., 68, 954-963.

665 Woollings, T., B. Hoskins, M. Blackburn, and P. Berrisford, 2008: A new Rossby 666 wave-breaking interpretation of the North Atlantic Oscillation. J. Atmos. Sci., 65, 609667626.

668 Woollings, T., A. Charlton-Perez, S. Ineson, A. G. Marshall, and G. Masato, 2010b: 669 Associations between stratospheric variability and tropospheric blocking. J. Geophys. 670 Res. - Atmos., 115, D06108, doi:10.1029/2009JD012742.

671 Zanchettin, D., S. W. Franks, P. Traverso, and M. Tomasino, 2008: On ENSO impacts 672 on European wintertime rainfalls and their modulation by the NAO and the Pacific 673 multi-decadal variability described through the PDO index. Int. J. Climatol., 28, 9956741006. 
677 FIG. 1. Left panels: Hovmöller diagrams (latitude-time) of the $850 \mathrm{hPa}$ zonal wind 678 component (in m.s-1), averaged over the $60^{\circ} \mathrm{W}-0^{\circ}$ longitude sector for the winters 679 (November-March) of 2010 and 2012. In both diagrams dark lines indicate the daily 680 latitudes of zonal wind maxima. Right panels: Corresponding histograms of the jet 681 latitudinal distributions for the winters of 2010 and 2012 (grey bars), along with the 682 average histogram over all winters in the period from 1950 to 2012 (white bars). The 683 frequencies of occurrence of each class are in days winter-1.

684 FIG. 2. Hovmöller diagrams (longitude-time) of the daily $500 \mathrm{hPa}$ geopotential height anomalies (in gpm) from the instantaneous zonal mean, averaged over the $40-50^{\circ} \mathrm{N}$ latitude sector, and for the winters (November-March) of (a) 2010 and (b) 2012.

FIG. 3. Left panels: Frequencies of occurrence of blocking (in percentage of days) over the North Atlantic and Europe for the winters (November-March) of (a) 2010 and (c) 2012. Right panels: Anomalies from climatology (1950-2012) of the blocking frequencies in (b) 2010 and (d) 2012, on the same color scale.

FIG. 4. First row panels: Composites of the 2-PVU potential temperature (in K) for the winters (November-March) of (a) 2010 and (b) 2012. Dashed line indicates the ridge axis. Lower left panels: Illustration of a cyclonic RWB episode in the 2-PVU potential temperature (in K) at 12:00 UTC for the period from 30 January 2010 to 3 February 2010. Lower right panels: Illustration of an anticyclonic RWB episode for the period 24 December 2011 (part of the 83rd SPRE in Table S1). 
the 1950-2012 baseline period. Middle panels: the same as on the upper panels, but for

700 the mean precipitation rates (in mm day-1). Lower panels: the same as on the upper 701 panels, but for the mean $2 \mathrm{~m}$ air temperature (in $\mathrm{C}^{\circ}$ ).

702

FIG. 6. Composite anomalies (baseline period of 1981-2010) of the: SST (shading in

703

${ }^{\circ} \mathrm{C}$ ) for October-November (a) 2010 and (b) 2012 (from NOAA Extended SST); 250

704

$\mathrm{hPa}$ zonal wind component (shading in $\mathrm{m} \mathrm{s}-1$ ) and $500 \mathrm{hPa}$ geopotential height

705 (contours in gpm) for November-March (c) 2010 and (d) 2012.

706

FIG. 7. Box plots of the (a) jet latitude and (b) number of SPRE days for all winters

707 (Nov-Mar) in 1950-2012 (NCEP) and 1871-2010 (20CR). Horizontal lines within the boxes indicate the medians, upper (lower) box limits the first (third) quartiles, upper (lower) whiskers the non-outliner maxima (minima). Red circles for outliers (above the

7103 th quartile $+1.5 \times$ interquartile range). Grey arrows locate the 2010 and 2012 winters

711 in the distribution. Chronograms of the (c) mean jet latitude and (d) number of SPRE days for winters in 1950-2012 (NCEP-NCAR reanalysis; black bars) and corresponding ensemble medians for winters in 1871-2010 (20CR; grey bars). Years refer to January

714 of each winter. The 11-yr running means (red curves) and the 11-yr running first/third

715 quartiles (blue curves) of the ensemble medians are plotted, along with the 11-yr

716 running means for the NCEP-NCAR (orange curves). 

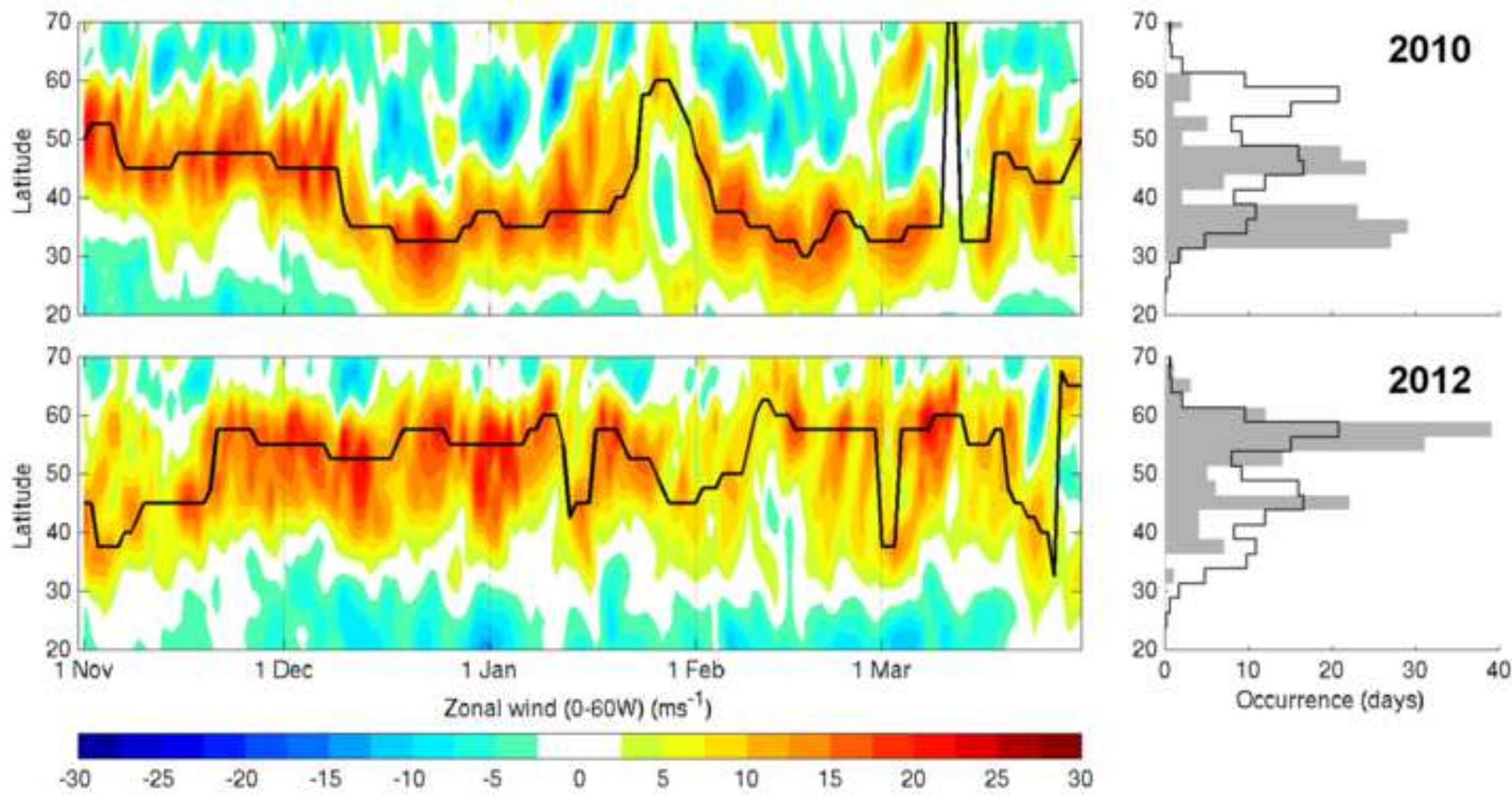
(a) 2010

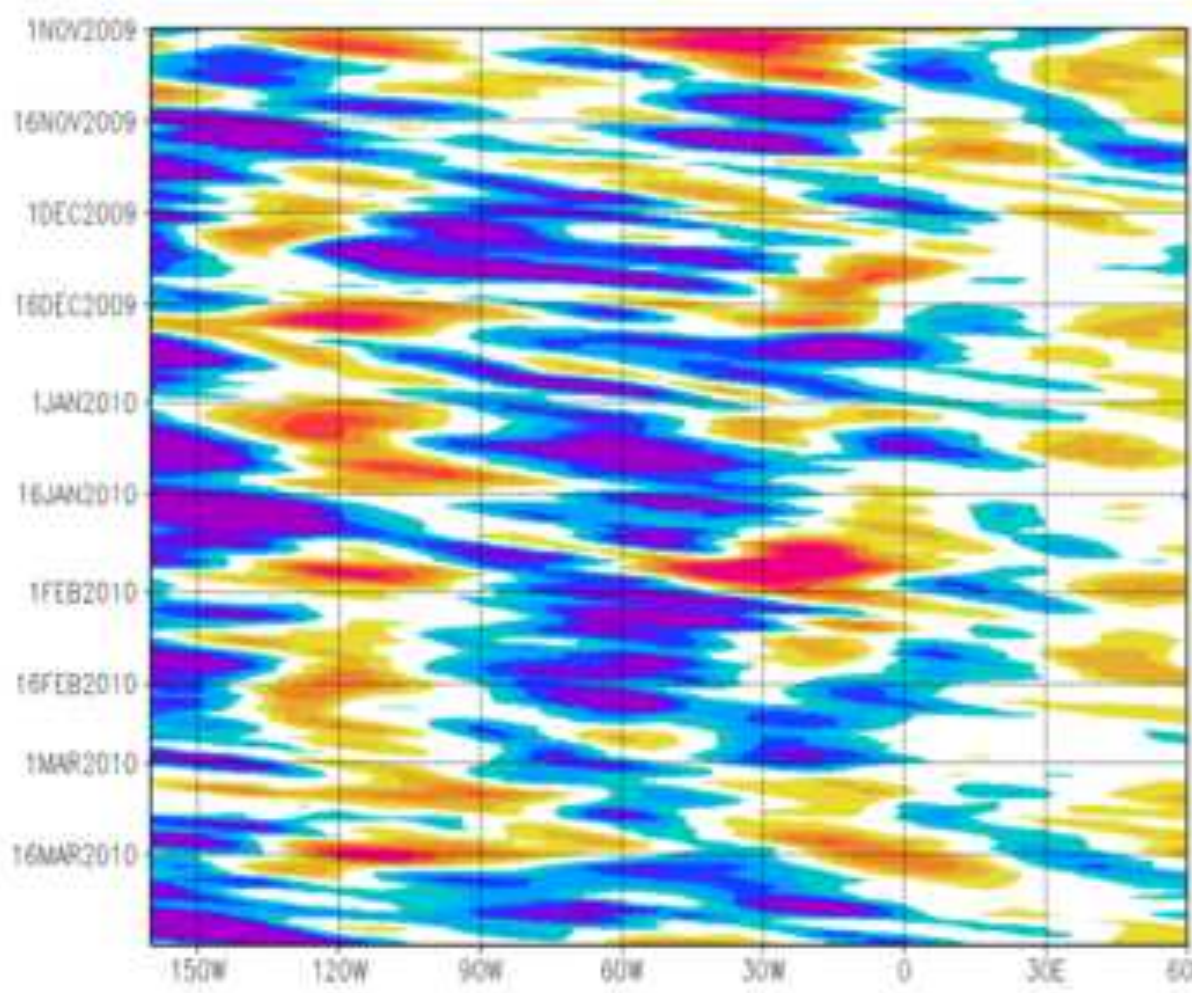

(b) 2012

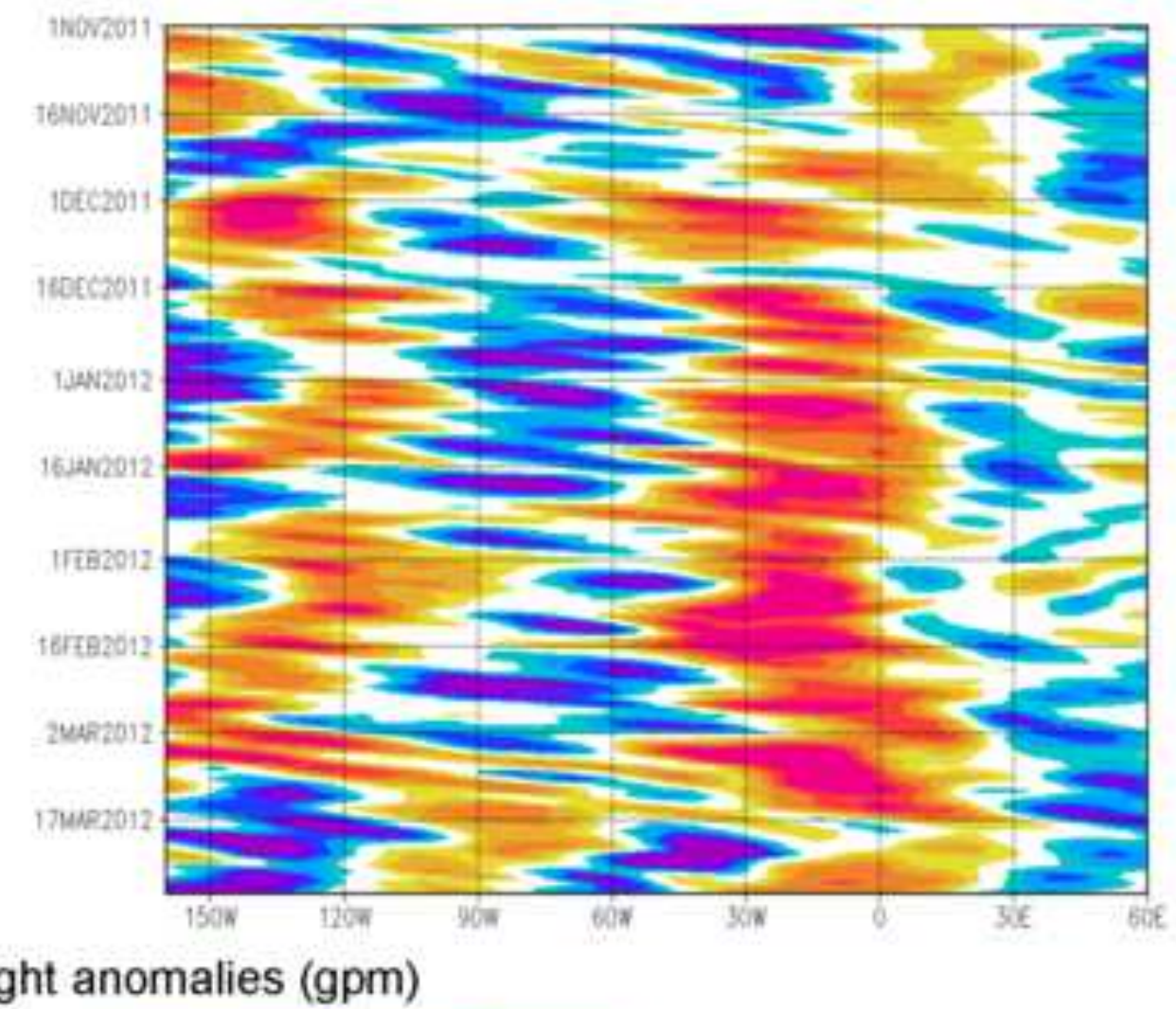

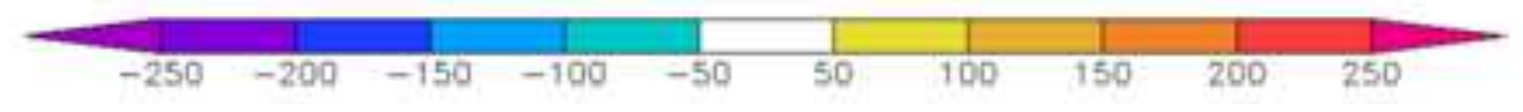


(a) 2010

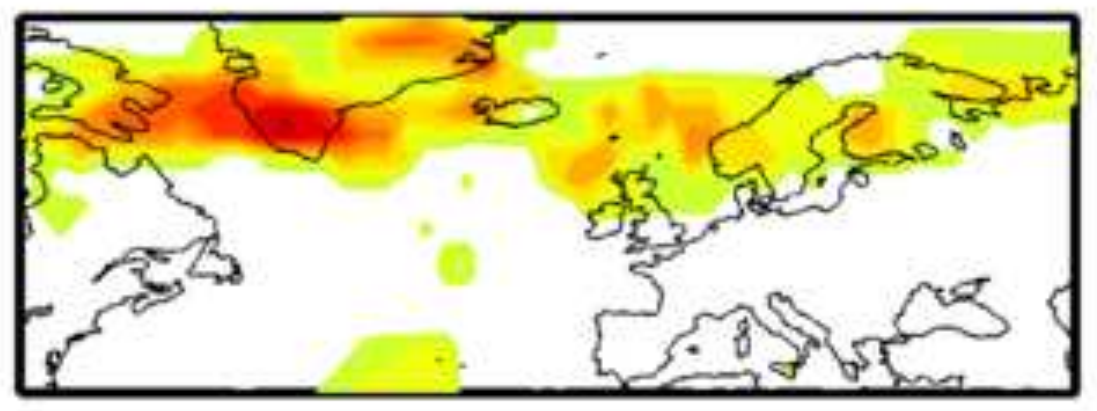

(c) 2012

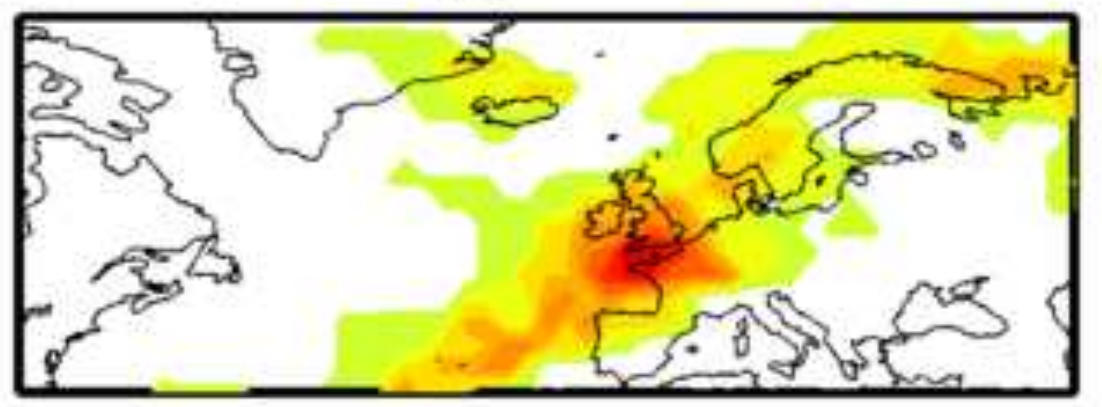

(b) 2010 anomalies

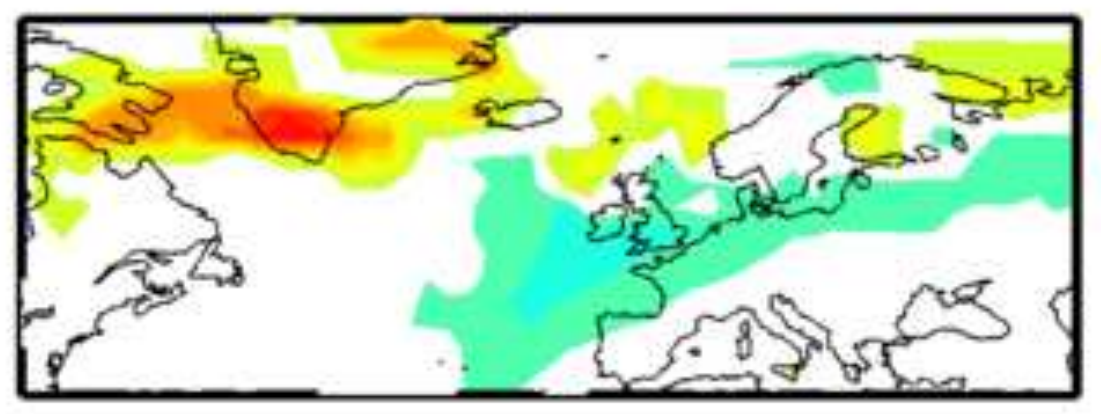

(d) 2012 anomalies

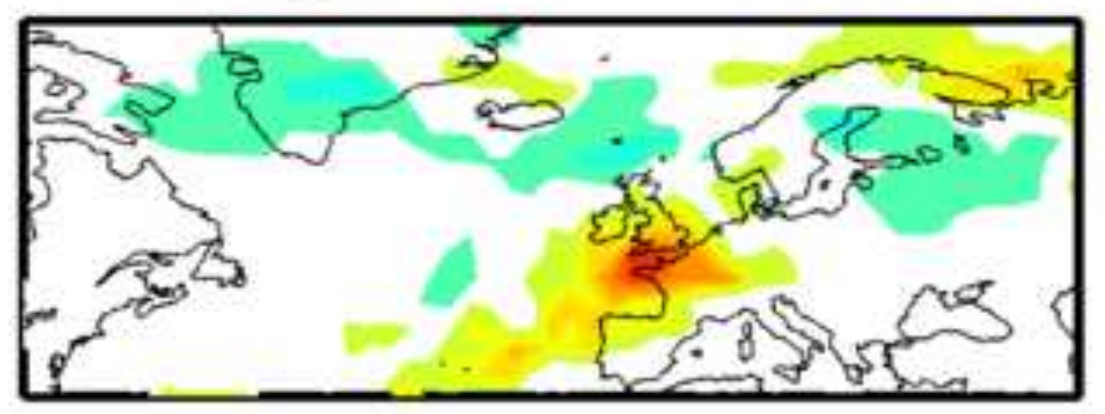

\section{Blocking frequency (\%)}

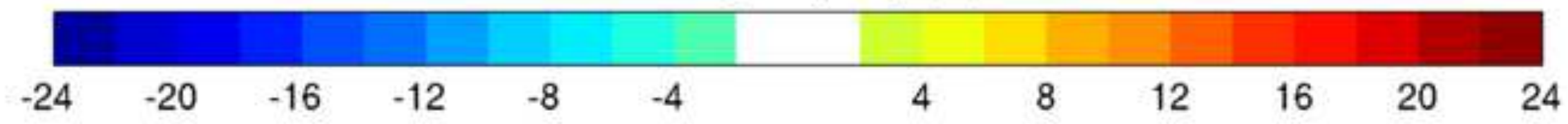


Rendered Figure 4

Click here to download high resolution image

(a) 2010

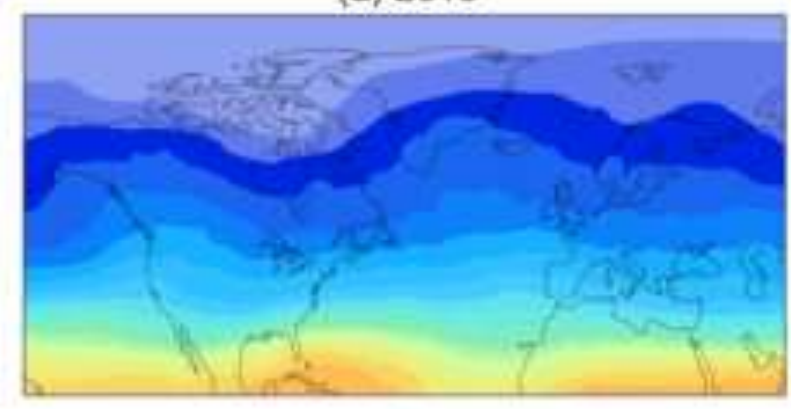

30 January $201012: 00$ UTC

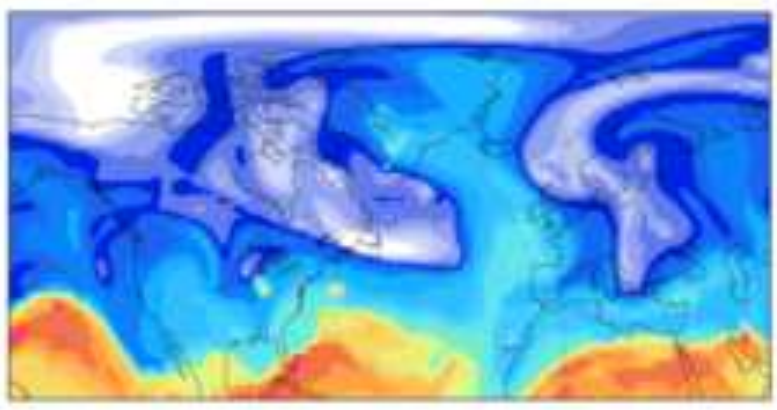

1 February 2010 12:00 UTC

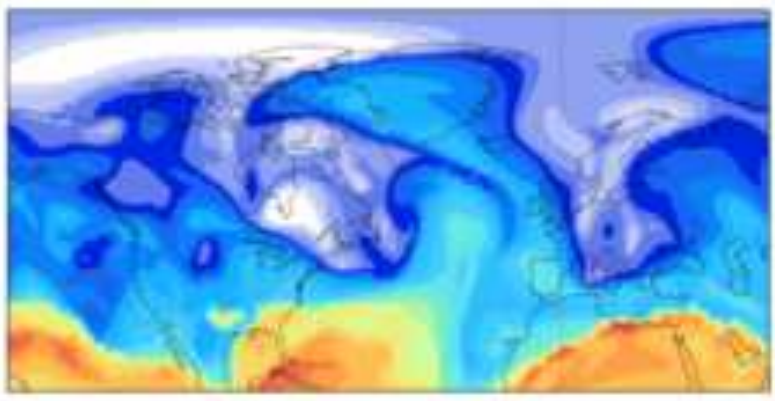

3 February 2010 12:00 UTC

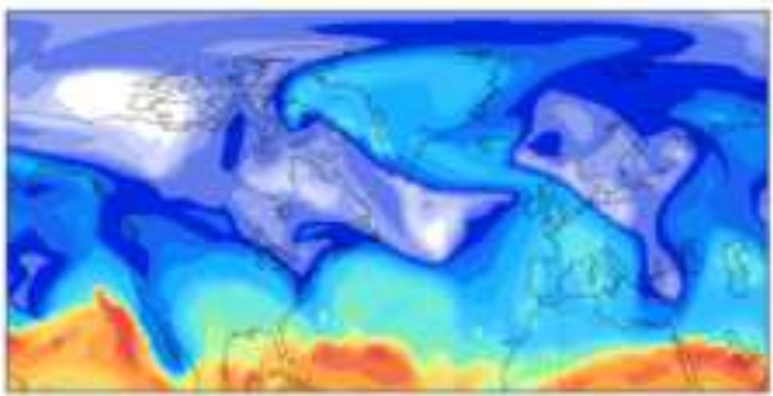

(b) 2012

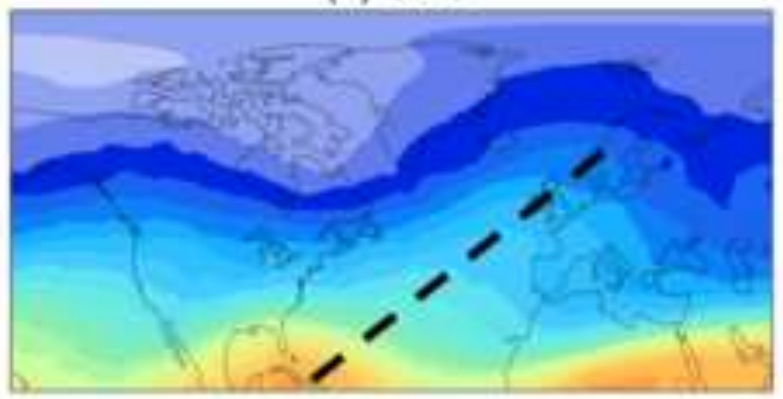

2 December 2011 12:00 UTC

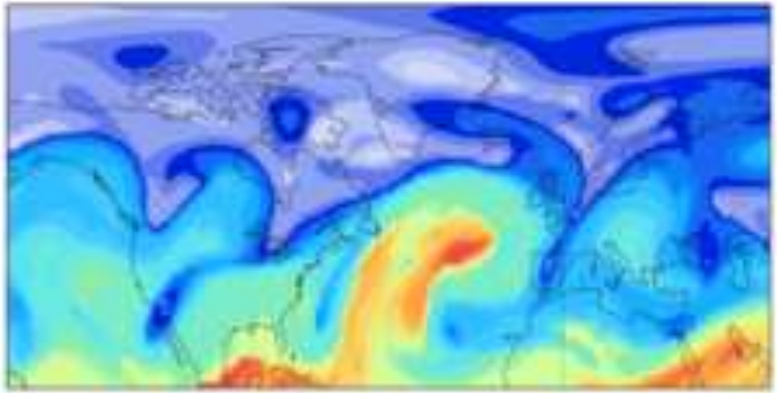

3 December 2011 12:00 UTC

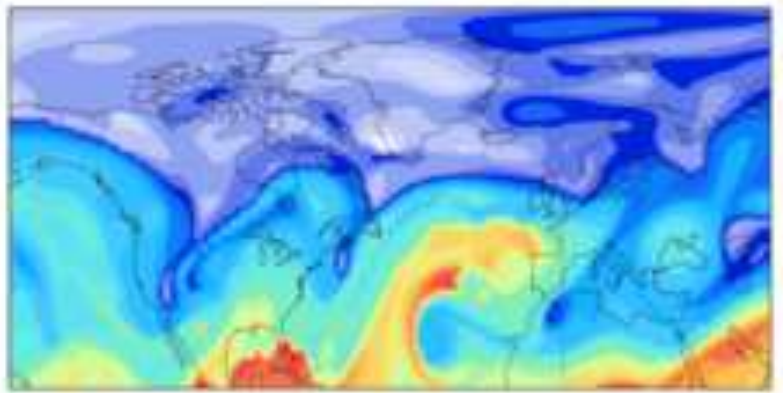

4 December 2011 12:00 UTC

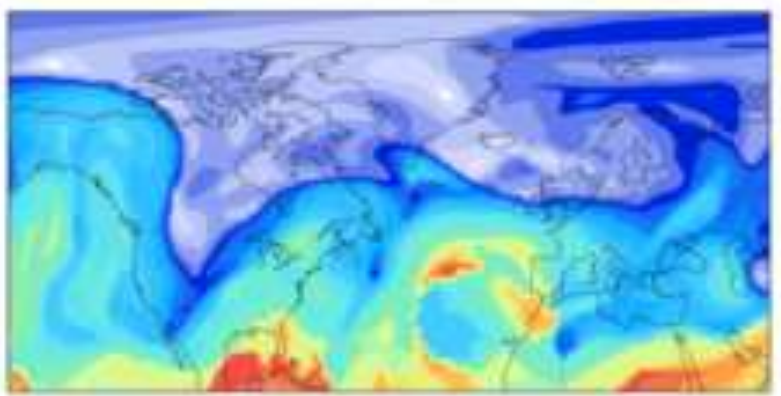

Potential temperacure (K)

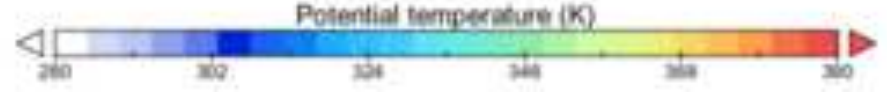


Rendered Figure 5

Click here to download high resolution image

(a) 2010

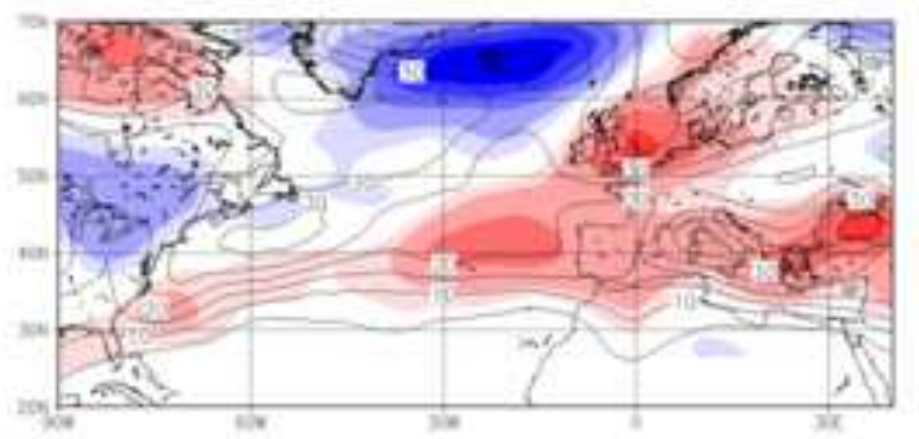

(b) 2012

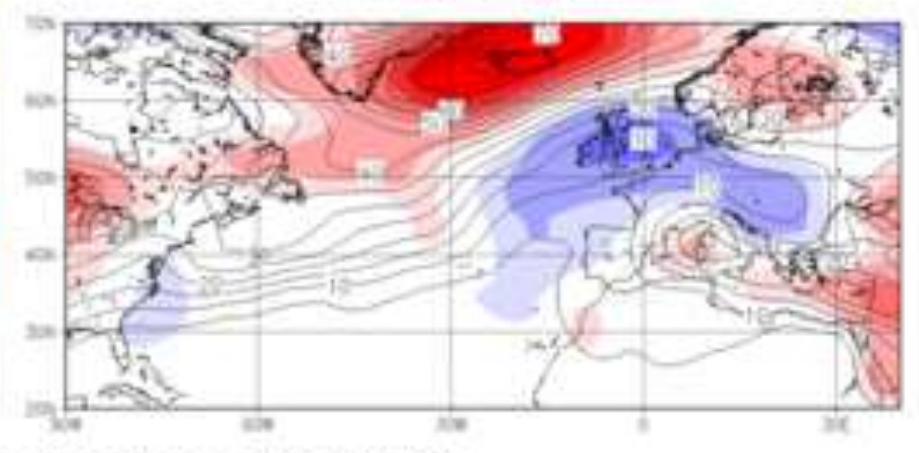

Cyclone track density anomalies (days winter ${ }^{1}\left({ }^{\circ} \text { at. }\right)^{-2}$ )
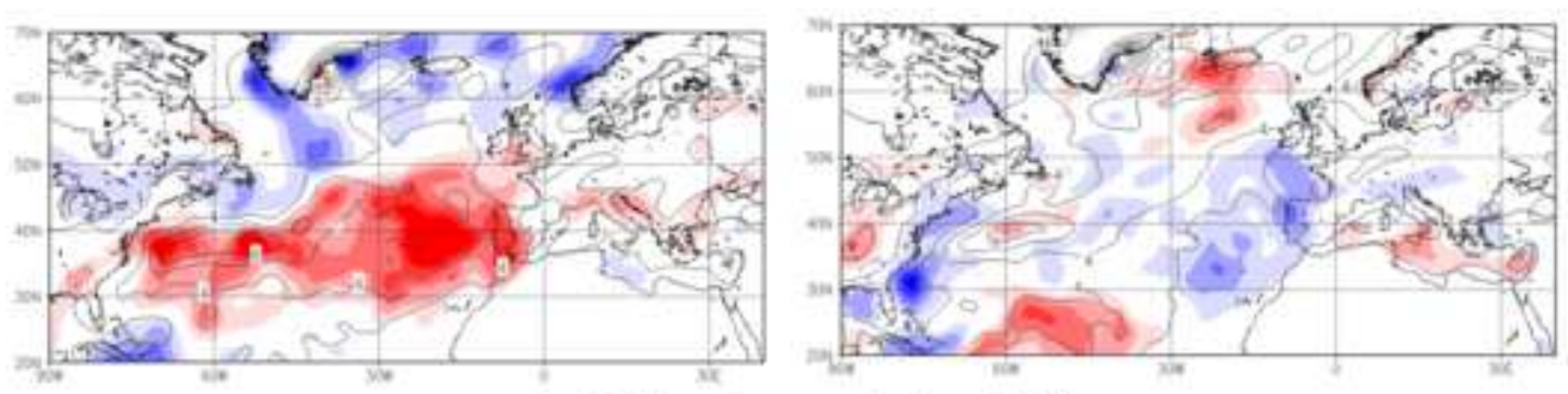

Precipitation rate anomalies (mm day')
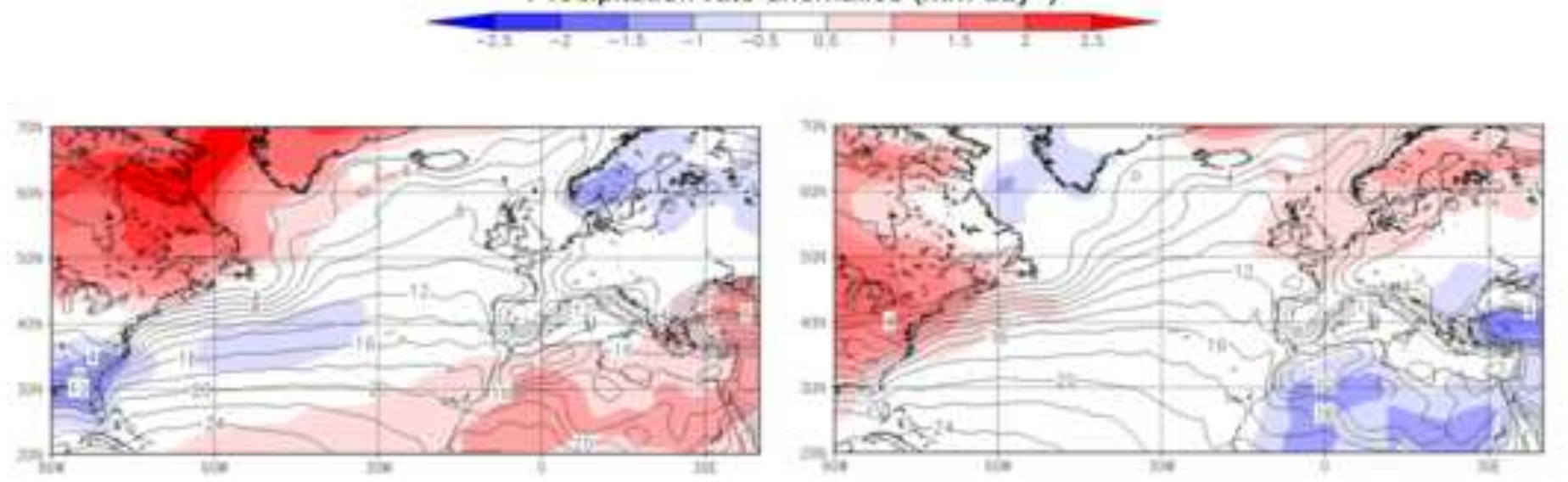

$2 \mathrm{~m}$ air temperature anomalies ( $\left.{ }^{\circ} \mathrm{C}\right)$

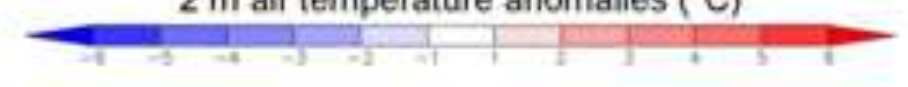


Rendered Figure 6

Click here to download high resolution image

(a) 2010

(b) 2012
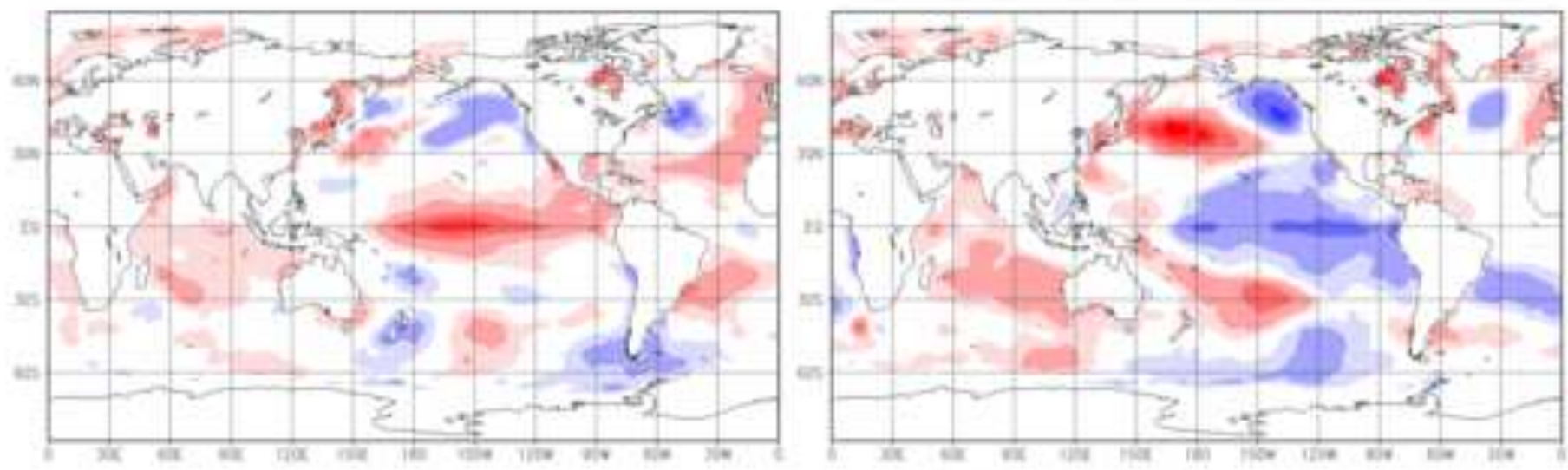

Sea surface temperature anomalies (Oct-Nov) $\left({ }^{\circ} \mathrm{C}\right)$

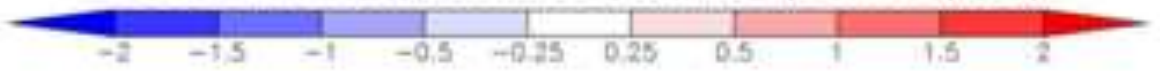

(c) 2010

(d) 2012
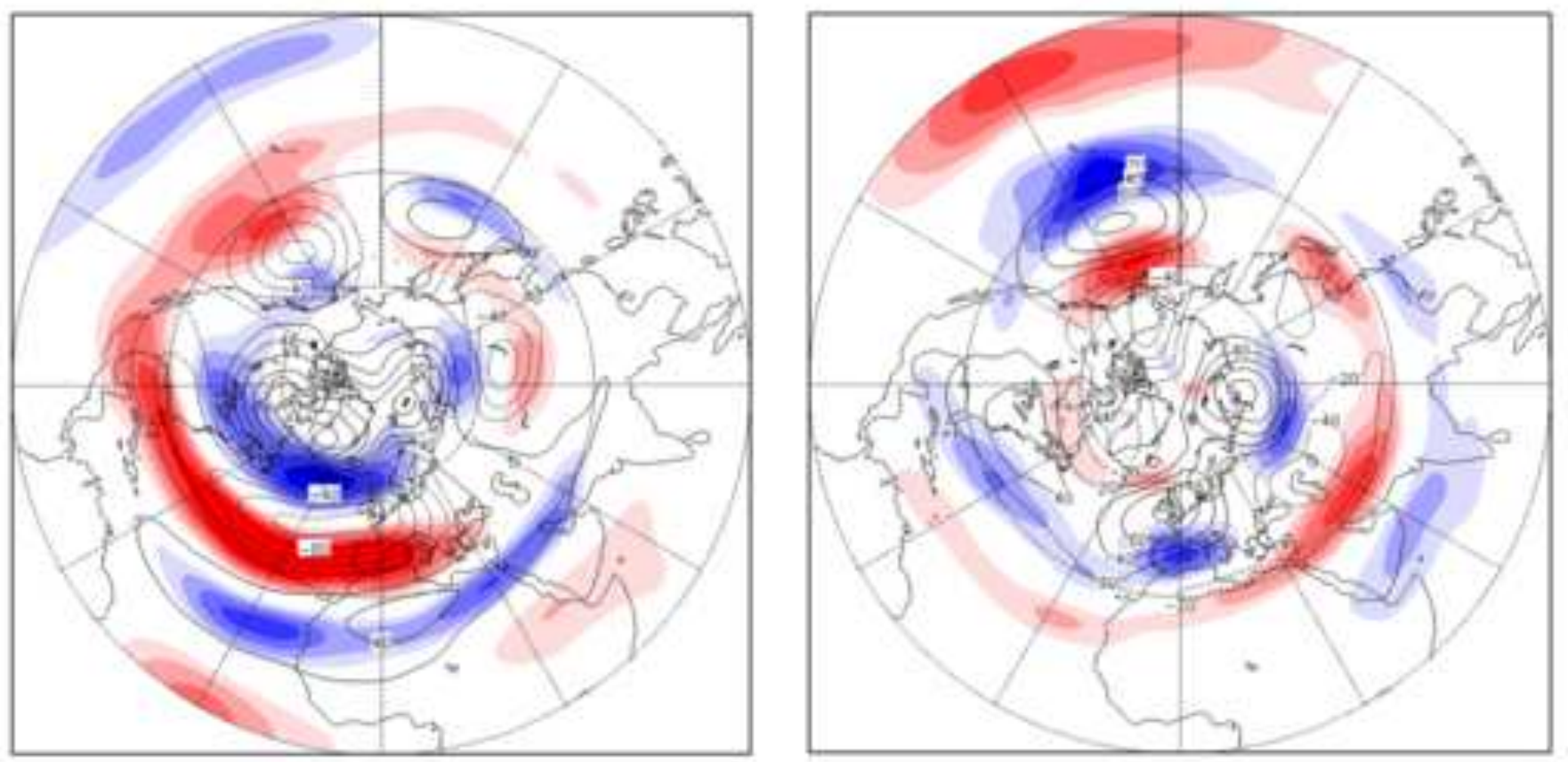

Zonal wind anomalies (Nov-Mar) $\left(\mathrm{m} \mathrm{s}^{-1}\right)$

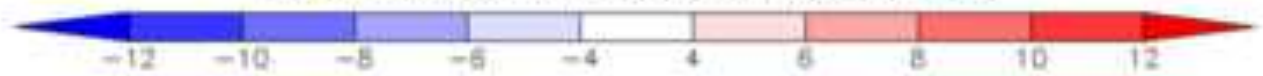


Rendered Figure 7

Click here to download high resolution image

(a)

(b)
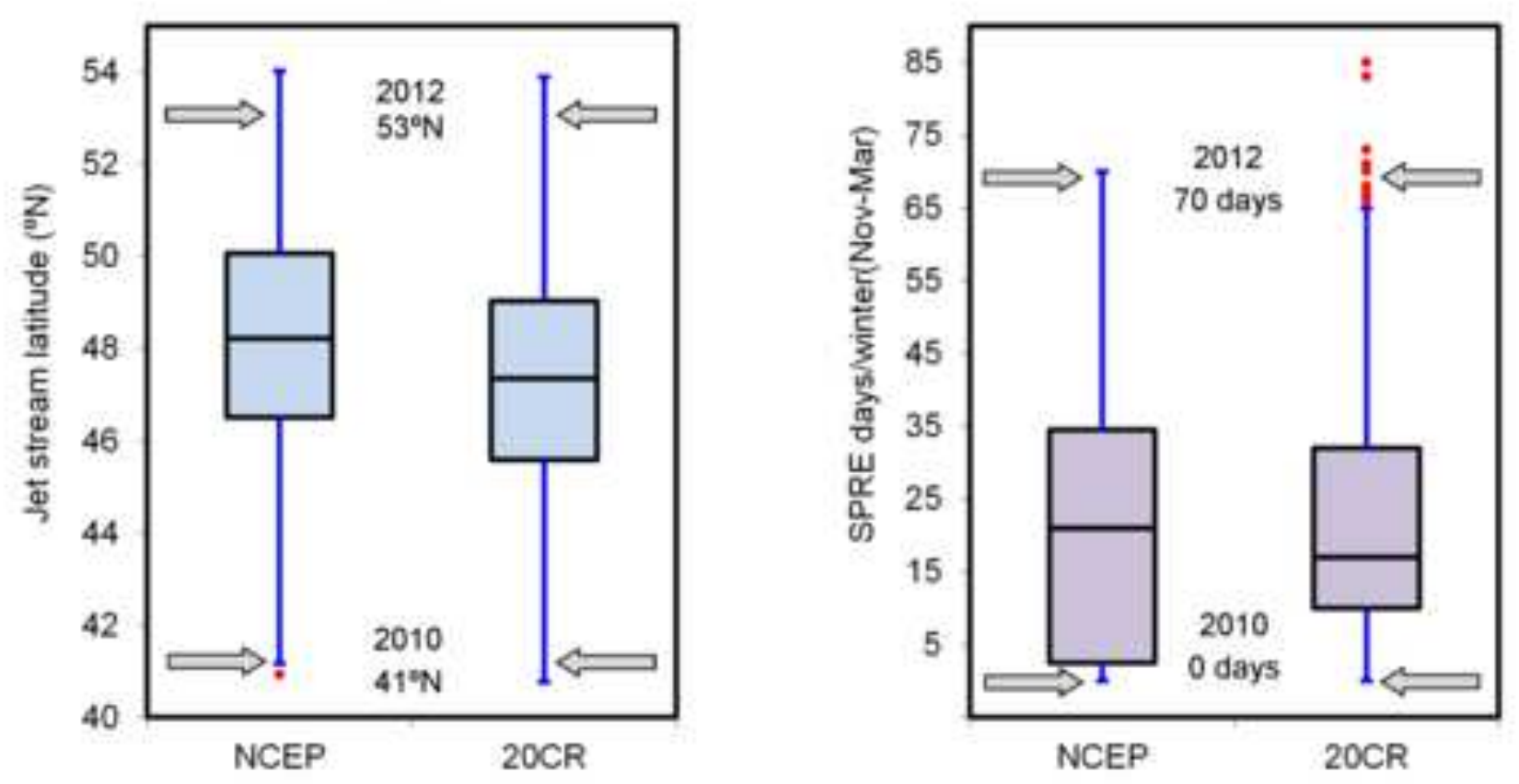

(c)

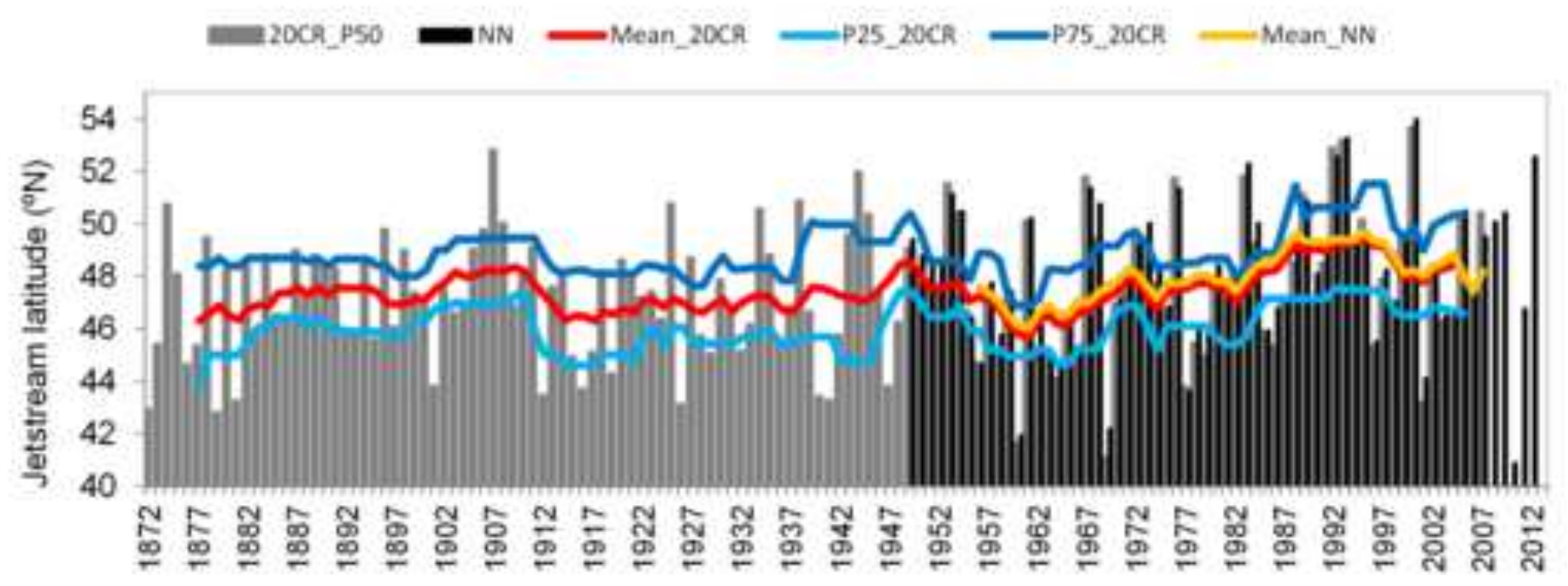

(d)

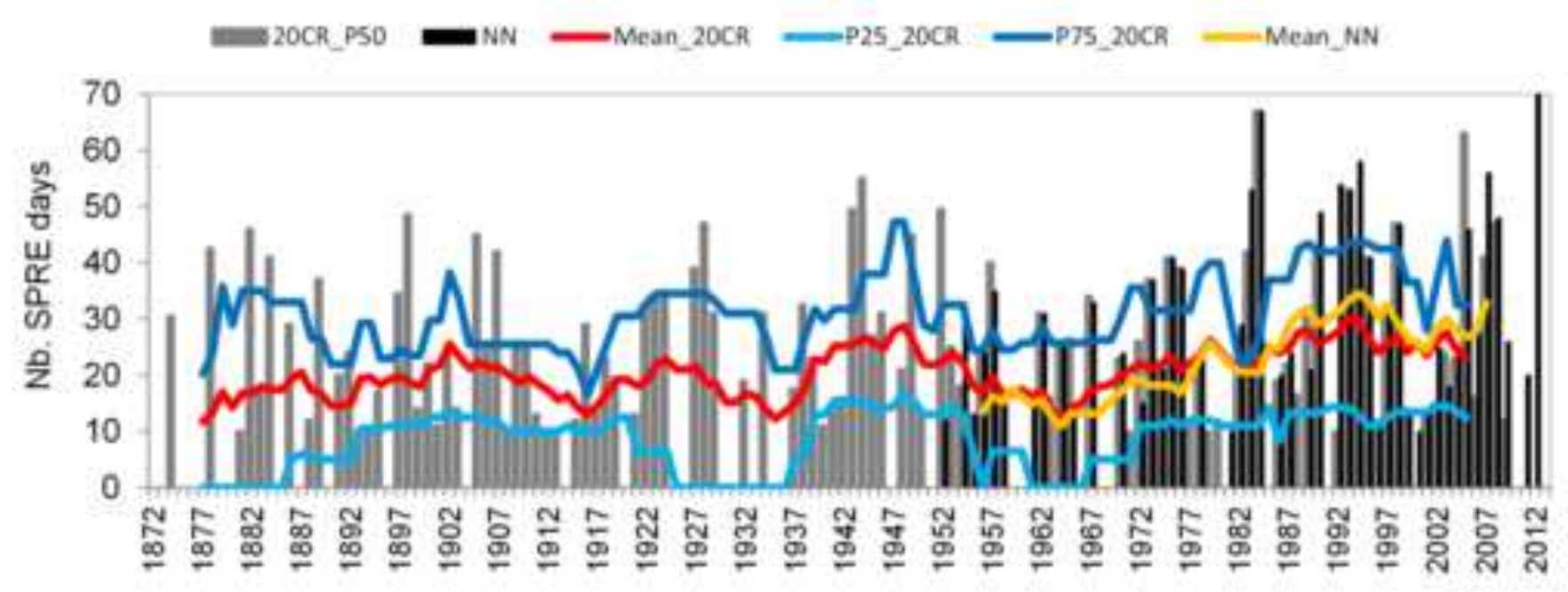


Supplemental Material
Click here to download Supplemental Material: SantosJA_etal_MWR_SupMat.doc

要 